\title{
A CASE STUDY OF LUNTIAN MULTI-PURPOSE COOPERATIVE IN BARANGAY LALAIG, TIAONG, QUEZON, PHILIPPINES: A VERTICAL INTEGRATIONAPPROACH
}

\author{
M. V. Perilla ${ }^{\mathbf{1}}$ J.M. Escala ${ }^{\mathbf{1}}$ and A. Setiadi ${ }^{\mathbf{1}, \mathbf{2}}$ \\ ${ }^{1}$ Department of Agribusiness Management, \\ College of Economic and Management, University of Philippines Los Banos, \\ College Laguna 4031-Philippines, ${ }^{2}$ Permanent address: Faculty of Animal Agriculture, \\ Diponegoro University, Tembalang Campus, Semarang 50275, Central Java - Indonesia \\ Corresponding E-mail: agus_setiadi2006@yahoo.co.id
}

Received July 26, 2009; Accepted August 18, 2009

\begin{abstract}
The Luntian Multi-Purpose Cooperative located in Tiaong, Quezon, Philippines. The Luntian MultiPurpose cooperative focuses more on feed production as well as hog fattening. The LMC applied the vertical integration to develop the cooperative. They have their members as their primary costumers of their feeds. The cooperative's business activity includes also meat shop, granting of production loan, microfinance, mobilization of saving deposits, aside from feed milling and hog fattening. Different agencies, industry organizations and private institutions provide trainings, seminars, assistance, as well as credit for the cooperative. The aims of the study was to determine the present and discuss a noteworthy business issue (s) of Luntian Multipurpose Cooperative, evaluate the business environment prevailing at a particular time of this case, assess the cooperative's performance in terms of the four business functions, define the problem relevant to the business issue(s) being studied. The study used primary and secondary data. Primary data were gathered through interviews with the key personnel, managers, and other informants of the Luntian Multipurpose Cooperative in order to obtain responses regarding the overall status of the cooperative including its problem and plans. Secondary data were taken from files and documents, especially the history, background information and financial statements. Other data were taken through research materials such as book, unpublished special problems and from some government institutions. The recommendation of this research showed that Luntian MPC should engage in establishing a communal farm as to become the primary source of hybrid piglets that their members would raised. The alternatives solution was establishing a breeding farm that would ask for initial investment.
\end{abstract}

Keywords: cooperative, vertical integration, case study, pork

\section{INTRODUCTION}

The number of registered mutual finance organizations or cooperative in the Philippines reached 68,922 in December 2004, 28,555 of them were considered operating. Today, there are cooperatives in almost all barangays or villages in the country. Since the passage of the Cooperative Code and the establishment of the Cooperative Authority (CDA) in 1990, the number of registered cooperatives in the country has increased $700 \%$. Before these twin laws were passed, there were only 8,620 of these associations.
Approximately, 94\% cooperatives in the Philippines are multi purpose cooperatives. They perform two main and integrated task namely financing and marketing. They also serve as the savings structure and sources of household and agricultural supplies of members. These cooperatives are predominantly agriculture based and agriculture oriented. As in the nature of mutual finance organizations, the resources of cooperatives in the savings, loans, and marketing sector come from the capital contribution of members as well as from profit from their credit, marketing, and other economic activities. 
The basic reason for having cooperatives, as a form of economic enterprise in an economy is to help people work together and move forward in a collective way. Cooperatives are considered to be the best form of economic enterprise because they are capable of seeking a balanced adjustment between collective spirit and individual rights. Most cooperatives were created due to the willingness of some people to expand their sources of credit, to help them establish their own marketing system and have the opportunity to share equally the incomes and benefits that are derived from the cooperatives.

Luntian Multi-purpose Cooperative was organized because small poultry and livestock raisers in Tiaong, Quezon realized the need to produce their own feed requirement for the stability and profitability of their business. The initiator thought that the members should have access to affordable, quality, reliable and stable supply of feeds for their hog operations.

The effort to increase the pork population depends on imports of feed ingredients, veterinary supplies, and exotic genetic material in most countries (Huynh et al., 2007). In particular this last concern may have assumed greater importance in location decisions for hog production because nutrient absorptive capacity may be the most site-specific of all necessary hog production inputs and because a firm's intended sitting of a large scale hog operation often serves as a focal point for local and regional discussions concerning the social efficacy of industrialized agriculture (Abdalla, Lanyon, and Hallberg in Roe et al., 2002).

Very large pork producers are commonly called "contractors" or "integrators" since they contract of their hogs out to independent growers (Reimer, 2006). LMC tried to provide the all input materials to produce the pork and also they have roles as marketer the output. In this case LMC applied the vertical integration function. Hart (1988) used vertical integration as a framework is generalized and adapted to the particular features of pork industry using surveys, statistics and case studies a guide (Hennessy, Lawrence in Reimer 2006)

The cooperative focuses more on feed production as well as hog fattening. They have their members as their primary costumers of their feeds. The cooperative's business activity include also running meat shop, granting of production loan, micro-finance, mobilization of saving deposits, aside from feed milling and hog fattening. Different agencies, industry organizations and private institutions provide trainings, seminars, assistance, as well as credit for the cooperative. Generally, this study aims to: 1) present and discuss a noteworthy business issue (s) of Luntian Multipurpose Cooperative; 2) evaluate the business environment prevailing at a particular time of this case; 3 ) assess the cooperative's performance in terms of the four business functions; 4) define the problem relevant to the business issue(s) being studied; 5) generate and evaluate alternative solutions to the identified problem; 6) identify the best solution using appropriate criteria and formulate recommendations for the cooperative.

\section{MATERIAL AND METHOD}

\section{Research Design}

Descriptive research design was employed. This design determined the patterns or characteristics of variables in a particular instance or events. As study needed some profiles, including personal and socioeconomic profiles of the members of the cooperative, descriptive research design was useful. It was also useful in assessing the core business functions namely marketing, personnel, and finance.

\section{Research Instrument}

The research instrument used in this study includes questionnaires or interview schedules. This will be used to have information about the insights of the manager, board of directors, committee head and members that lead to some business and problems that the cooperative is currently facing.

\section{Method of Data Collection}

The study used primary and secondary data. Primary data were gathered through interviews with the key personnel, managers, and other informants of the Luntian Multipurpose Cooperative in order to obtain responses regarding the overall status of the cooperative including its problem and plans.

Secondary data were obtained from files and documents that the cooperative provided to the researcher especially the history, background information, and financial statements. Other data were taken through research materials such as book, 
unpublished special problems and from some government institutions.

\section{Method of Data Analysis}

The four areas of management were evaluated and analyzed to determine the main problems of the cooperative. SWOT analysis was also done to present the company's strengths, weaknesses, opportunities, and threats. The data was analyzed to come up with alternative strategies that were used in the decisionmaking tools.

Financial ratios were used in analyzing the financial situation of the company to determine the liquidity, solvency, and profitability of the company's operation. As financial ratios were calculated and interpreted, the cooperative's performance was assessed. Secondary data such as information regarding the firm's environment were analyzed using the macro and microenvironment analysis.

\section{RESULTS}

\section{Operation}

Luntian center and some part of region IV need to increase their production of feeds. Feed mill plant and warehouse of the cooperative was not enough to accommodate the number of bags of feeds that they need to produce everyday. In hog fattening operation, the cooperative experience problems in member who failed to report regularly in the office especially those members who have filed loans in feeds, that was supposed to be payable after four months.

\section{Personnel}

The cooperative now experiencing about $40 \%$ members that were not attending meetings or general assemblies that was done quarterly. This would affect the awareness of the members regarding the cooperative's activities and their policies. The cooperative also had poor handling of accounting on internal auditing process. At present, the cooperative still hires an accountant or auditor who assists the committee in charge of accounting and auditing.

\section{Marketing}

The cooperative did not have its own breeding farm to become the source of piglets that the members may use in hog raising. With this, there was no assurance in the quality of piglets.

\section{Finance}

The cooperative's source of fund were mainly come from the member's contribution. They also had loans from the land bank of the Philippines and to other organizations as an alternative source of funds for the activities of the cooperative.

\section{SWOT Analysis}

1. Strengths

a. The cooperative had its own land, facilities and equipment used in their business operations.

b. They had different business activities that help them generate profit and serves as a source of capital for the cooperative.

c. Strong support and assistance from different organizations.

d. The cooperative experienced an increasing number of members.

e. Luntian MPC was financially stable.

f. Some of founding members were still part of the management of the cooperative

\section{Weaknesses}

a. Lack motivation for members.

b. Some members of the board of directors did not have enough knowledge and educational background about the operations of the cooperative and some business activities

c. At present, the cooperative is experiencing limited patronage of its products and services from their members.

d. The cooperative did not have enough space for feed production and warehousing.

e. The cooperative did not give cash loans

f. The cooperative now experiencing difficulty in sourcing of hybrid piglets

\section{Opportunities}

a. There was an increasing demand for products and services as well as for credit

b. The presence of government and nongovernment institutions that supports cooperatives. 
c. Increasing awareness of the people in the cooperative and the benefits that it could offer. d. The increased price of processed meat offered in the market

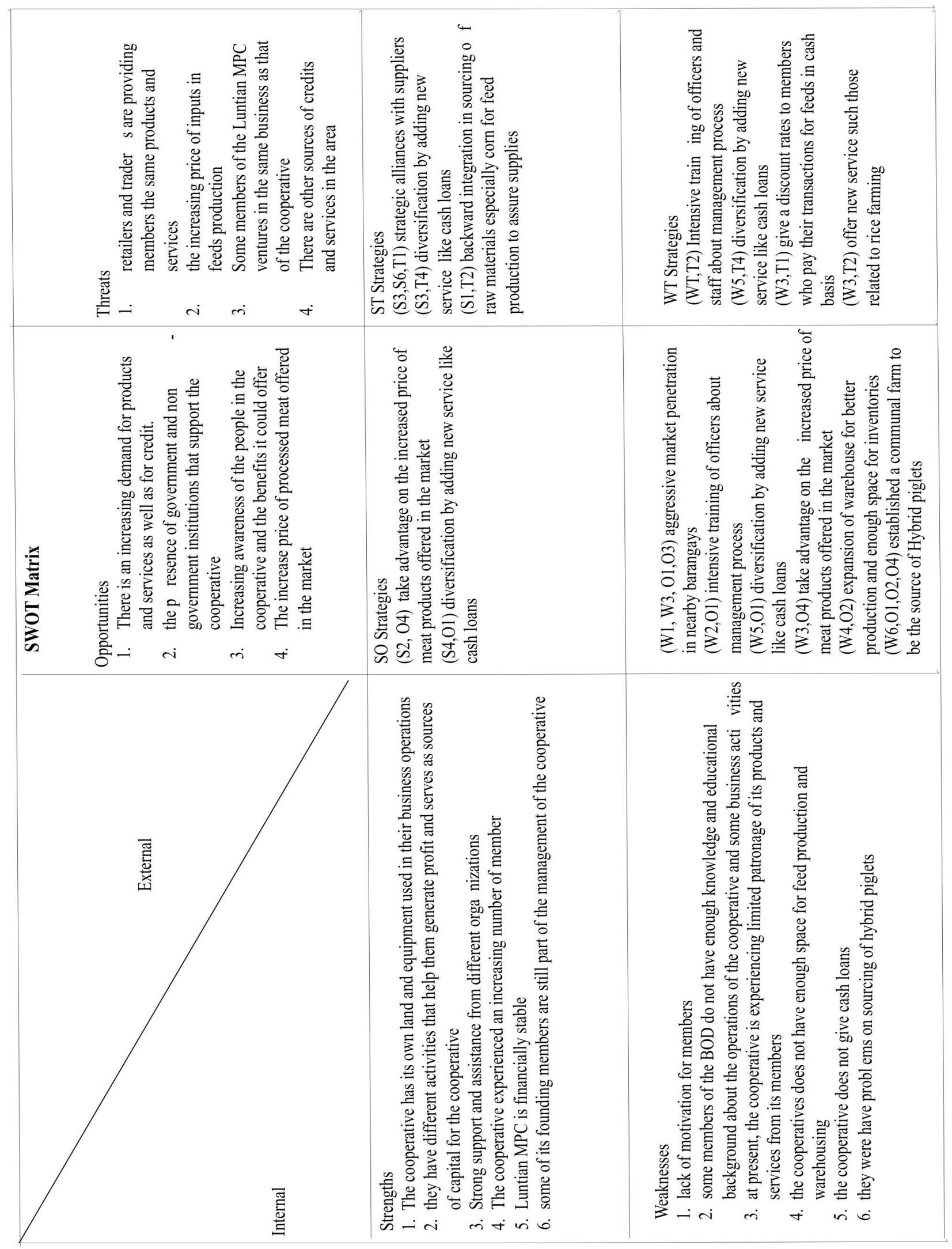


4. Threats

a. Retailers and traders are providing members the same products and services

b. The increasing price of inputs in feeds production

c. Some members of Luntian ventures in the same business as that of the cooperative

d. There were other sources of credits and services available in the area

\section{DISCUSSION}

The alternatives were developed by matching the strengths, weakness, opportunities and threats in the SWOT Matrix. In this case, all alternatives were derived based on the major problem that was identified. Since the cooperative is currently experiencing a decreasing patronage from its members and has a problem regarding the marketing and production efficiency of its products and services, it would definitely affect the profitability performance of the cooperative. For this problem, the researcher came up with the following alternatives:

1. Diversification by offering new service for members

The increasing number of needs by farmermembers could be an opportunity for the cooperative to add new service like cash loans. Since not all members do hog rising, the cooperative could help them engage in other business by providing them capital through cash loans. With this service, additional income for the cooperative will be generated. This will encourage participation of inactive members engaging in other business, thus will help to increase patronage for cooperative. The cooperative had a good credit standing with banks like Land Bank of the Philippines, they will not have any problem in capital requirement. This will increased the financial status of the cooperative, provided that they will become efficient in loan collection.

2. Backward integration in sourcing of the raw materials for feed production.

This alternative spares the cooperative the uncertainty of being dependent on suppliers and it lessens their vulnerability to unreasonable supplier's price increase. It would help them to achieve greater cost savings and performing in house production of the raw materials specifically corn, might help them to produce better quality feeds. Since the cooperative needs to produce large volume of feeds to cater the demands, there is an assurance for corn supply. The demand for corn is now increasing, so competition for this material was very high. It will be better for them to produce their own for continuous production.

\section{Aggressive market penetration}

The cooperative may conduct seminars in nearby barangays to give the products and services offered. They may provide their resident members flyers showing the different products and services that the cooperative has. Flyers should include prices of feeds and meat products for them to know that they offer lower prices compared with other product. The seminar should include giving information of the current performance of the cooperative to give an idea for those members who were not regularly attend meeting. Discussions also on the effects of having high patronage on its products and services would be a help for the cooperative to gain and increase participation from their members. In this way, members become aware of the possible effects of their increased participation in the cooperative. This alternative will also help them to attract new costumers to avail their products. It would help them enhance its chances of increasing its profit.

4. Establishment of communal farm to become the primary source of hybrid piglets

One major of the cooperative that resulted to the delinquency and delayed of the members in paying their loans on feeds in the difficulty in sourcing of their piglets. Member who venture in this operation did not have a complete guarantee that their animal will grow uniformly and at the expected time. Sometimes they get piglets that were of inferior quality. This alternative will requires the cooperative a lot of preparation in terms of location of the breeding farm, the probable source of good variety of pigs to be produced and the necessary veterinary requirements.

\section{CONCLUSION AND RECOMMENDATION}

Preference was used to evaluate each alternative given to come up with the recommended strategy for the problem of the cooperative regarding the inefficiency of its production and marketing operations especially in their hog raising. It was recommended 
that Luntian MPC should engage in establishing a communal farm as to become the primary source of hybrid piglets that their members will raised.

The alternative ranks the highest among the other alternative as they were evaluated according to the criteria. This alternative was chosen for being the most beneficial to farmer-members since they will be assured of the quality of piglets they will raised. Since the chosen alternative will not only benefit the cooperative but also the farmer-members, this will also imply ease of implication because of the support from the members. In terms of its cost, establishing a breeding farm would ask for initial investment. In the long run, this will help address their problem.

If selected alternative which is to establish the cooperative's own communal or breeding farm become unviable, Luntian Multi-purpose Cooperative may implement Alternative 1 which is offering new service such as giving of cash loans for members and engaging to business that is related to rice faming. This alternative could help other members to engage in other business. This will also encourage participation of inactive members engaging in other business, thus will help to increase patronage for the cooperative. This service gives additional income for the cooperative and will improve the current performance of cooperative in terms of their services given to their members as well as to non members.

\section{REFERENCES}

Anciano, G.P. 2007. A case study of Palangue Agrarian Reform Cooperative: Unpublished Undergraduate Special Problem. UP Los Banos Adlai, E. S. 2004, Regional financial cooperation in Asia. J. Asian Econ. 15: 837-841

Anonim, 2007, Contract Farming of Swine in

Southeast Asia as a Response to Changing Market Demand for Quality and Safety in Pork, IFPRI Discussion Paper 00779

Barcelona, J. A. 2004. Case Study of the Batanes Multipurpose Cooperative Incorporated Unpublished undergraduate Special Problem. U.P. Los Banos.

Belarmino, J.P. A. 2005. A case study of MARILA Multi - purpose Coopearive in San Pablo City : Unpublished Undergraduate Special Problem. UP. Los Banos.
Boehlje, M. 1995. Vertical coordination and structural change in the pork indutry. Am. J. Agric. Econ. 77: $1225-28$

Bogetoft, P. and H. Olesen. 2004. Quality incentives and supply chains: Managing salmonella in pork. Am. J.Agric.Econ. 86:829-34

Catampatan, R. R. 2002. A case Study of Tanay market Vendors and Community Multi-purpose Cooperative in Tanay, Rizal Unpublished Undergraduate Special Problem. U.P. Los Banos Fackler, P.L and H. Tastan. 2008. Estimating the degree of market integration. Am. J. Agric. Econ..90(1): 69-85

Getnet, K., W.Verbeke and J. Viane. 2005. Modelling spatial price transmission in the grain markets of Ethiopia with an application of ARDL approach to white teff. Agric.Econ.33:491-502

Goodwin, B.K and N.E. Piggott. 2001. Spatial market integration in the presence of threshold effect. Am. J. Agric. Econ. 83:301-317

Groningen, C.V., C.J.B. Devitt, J.W. Wilton and J.A.L. Cranfield. 2006. Economic evaluation of beef bulls in an integrated supply chain. J. Anim. Sci. 2006.

Hart, O. 1988. Incomplete contracts and the theory of the firm. J. Law, Econ. and Organization 4:11939

Hennessy, D.A. 1996. Information asymmetry as a reason for food industry vertical integration. Am..J.Agric. Econ.78:1034-1043.

Hubbel, B.J. and R. Welsh. 1998. An examination of trends in geographic concentration in U.S. hog production, 1974-96. J. Agric.Appl. Econ. 30 :28599

Huynh, T.T.T., A.J.A. Aarnik, A.Drucker and M.W.A. Verstegen. 2007. Pig production in Cambodia, Laos, Philippines, and Vietnam: A Review. Asian J.Agric. Dev. 4(1): 323-339

Jordan, K. H. and J. J. VanSickle. 1995. Integration and behavior in the U.S. winter market for fresh tomatoes. J. Agric.Appl. Econ. 27(1): 127-37.

Kleibenstein, J. and J.D. Lawrence. 1995. Contracting and vertical coordination in the U.S. pork industry. Am. J. Agr. Econ. 77:1223-18

Malagday, S.F. 2005. A case Study of claveria Farmers Multipurpose Cooperative. Unpulished Undergraduate Special Problem. U.P. Los Banos. 
Mc New, A. and P. L. Fackler. 1997. Testing market equilibrium: Is cointegration informative? J.Agric.Resource Econ. 22 (2): 191-207

Miller, D.J and M. L. Hayenga. 2001. Price cycles and asymmetric price transmission in the U.S. Pork Market. Am..J. Agric.Econ. 83(3): 551-562

Roe, B., E. G. Irwin and J. S. Sharp. 2002. Pigs in space: Modeling the spatial structure of hog production in traditional and nontraditional production regions. Am.J.Agric.Econ.84: 259278.

Reimer, J.J. 2006. Vertical integration in the pork industry, Amer. J. Agr. Econ. 88(1): 234-248

Rhodes, V.J. 1995. The industrialization of hog production. Rev.Agric. Econ.17:107-18

Whinston, M. 2003. On the transaction cost determinants of vertical integration. J.Law, Econ. and Organization 19:1-23 
